How to cite: UNEŞ, F., DEMIRCİ, M., VARÇIN, H. (2020) Estimation of Dam Reservoir Volume Using Neural Networks. 2020 "Air and Water - Components of the Environment" Conference Proceedings, Cluj-Napoca, Romania, p. 191-200, DOI: 10.24193/AWC2020_18.

\title{
ESTIMATION OF DAM RESERVOIR VOLUME USING NEURAL NETWORKS
}

\author{
Fatih UNEŞ $S^{1}$ Mustafa DEMIRCI' ${ }^{1}$, Hakan VARÇİ ${ }^{1}$
}

DOI: 10.24193/AWC2020_18

\begin{abstract}
Dam reservoir capacity estimations are important for operation, design and safety assessments of dam structures. In this study, the reservoir capacity of the Stony Brook dam in US state of Massachusetts was tried to be estimated with data taken from US Geological Survey Institute (USGS). Reservoir capacity was estimated by using two types Neural Networks, namely, Artificial Neural Networks (ANN), Generalized Neural Networks (GRNN), and also Multi Linear Regression method (MLR) models. The model results were compared with measurements by calculating Mean Square Error (MSE), Mean Absolute Error (MAE), correlation coefficient statistics.
\end{abstract}

Keywords: Estimation, Artificial Neural Networks, Reservoir, Multiple Linear Regression

\section{INTRODUCTION}

Accurate operation of the reservoir volume of the dam is provided by the correct collection of water at the right time and the accurate estimation of its changes. Floods caused by improper operation of the reservoir and insufficient precautions may result in loss of life and property.

Therefore, proper dam reservoir management is not only a requirement for fresh water supply, but also for the prevention of potential damages. In order to manage the reservoir correctly, it is necessary to accurately estimate reservoir water volume and temporal changes.

The dam reservoir volume is affected by several parameters such as drainage area, precipitation, seepage, runoff, evaporation, and irrigation. All of these parameters must be continuously measured for many years to manage the dam reservoir.

In the past, classical traditional methods have been used to estimate the change of the reservoir volume. In these methods, reservoir volume has been defined with mass conservation (continuity equation) at macro scale in hydrologic investigation systems. Recently, artificial intelligent techniques have been used in water research engineering.

\footnotetext{
1 Iskenderun Technical University, Civil Engineering Department, fatihunes66@gmail.com mustafa.demirci@iste.edu.tr hakan.varcin@iste.edu.tr
} 
Artificial Intelligence techniques are frequently used in hydraulic and water researches due to the non-linearity of the related problems (Chen, 2012; Nivesh et al., 2018; Demirci et al., 2018a; Demirci et al., 2018b; Kaya et al., 2018; Talei et al., 2013; Taşar et al., 2018; Kaya and Tasar 2019).

The Artificial Intelligence models were applied by researchers to investigate the reservoir level fluctuations (Üneş et al., 2019a; Üneş et al., 2019b). Some researchers used artificial intelligence techniques to predict of density flow plunging depth in dam reservoirs (Üneş et al., 2015b). Üneş et al. (2018b) also used ANN to predict daily reference evapotranspiration measurements. Taşar et al. (2017) predicted suspended sediment in rivers by using artificial intelligence models. Üneş et al. (3013; 2018b) used SVM and ANFIS to predict dam reservoir volume fluctuations. Üneş et al. (2018a) applied artificial intelligence techniques to estimate of RainfallRunoff relationship.

The ANN models were applied by many researchers to investigate the precipitation and discharge relationship in reservoirs (Hallf et al., 1993; Smith and Eli, 1995; Hsu et al., 1995; Kumar et al., 2002; Wilby et al., 2003; Solomatine and Dulal, 2003). Karuhunanithi et al. (1994), Dawson and Wilby (1998), Campolo et al. (1999) and Imrie et al. (2000) have shown that ANN can be used in river flow estimates. In recent years, studies on the physics of ANN have been published. Jain et al. (2004) investigated the ANN physics that were placed into the correlation weights of the ANN. Sudheer and Jain (2004) attempted to explain the intrinsic behavior of the artificial neural network with river flow models. Sudheer (2005) tried to construct river models with information extracted from trained neural networks.

This study attempts to estimate the reservoir capacity of the Stony Brook dam in Massachusetts, USA. Temperature, precipitation flow and past dam reservoir volume data were used to compare the reservoir capacity with ANN, GRNN and MLR models and compare the models with each other. The present study aims to obtain the most appropriate operating and storage capacity for a multipurpose dam reservoir.

\section{DATA AND METHODS}

\subsection{Application area}

Stony Brook Dam in Massachusetts, USA was selected as application area. The Stony Brook dam is located in Middlesex County, Massachusetts with $42^{\circ} 35^{\prime}$ '46.3' $\left(42.5962^{\circ}\right)$ degree latitude and $71^{\circ} 26^{\prime} 18.7^{\prime}$ ' $\left(71.4385^{\circ}\right)$ degree longitude (Figure 1). Drainage area is $70.7 \mathrm{~km} 2$. The Stony Brook Reservoir reaches a maximum height of 68.9 feet, the deepest point about 30 feet, and roughly 425 million gallons of water at full capacity. Stony Brook is relatively small compared to the large basin and is much faster than other dams. Daily air average temperature, precipitation, river inflow, lag time reservoir volume is taken from Stony Brook Dam as inputs and reservoir volume as output for the created models. 


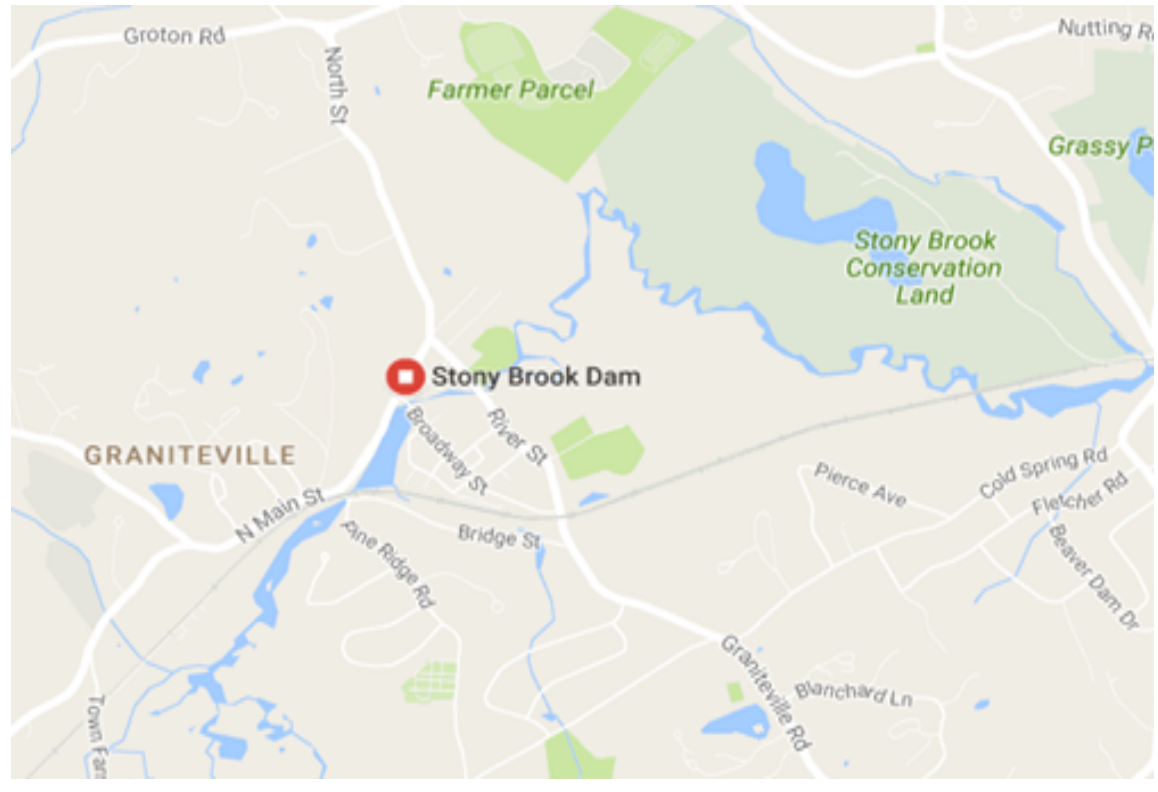

Fig. 1. Overview of Stony Brook Dam (after Google Maps, 2020)

\subsection{Model results}

Artificial neural networks (ANN), Generalized neural networks (GRNN), and multiple linear regression (MLR) models were created and the results were evaluated.

For each model, the mean square error (MSE), the mean absolute error (MAE) and the correlation coefficients $(\mathrm{R})$ between the observed values and estimations were calculated, and the results were used to compare the performance of the model estimation and observation data. MSE and MAE are determined as follows.

$M S E=\frac{1}{N} *\left(\sum_{i=1}^{N} Y i_{\text {observed }}-Y i_{\text {predict }}\right)^{2}$

and

$M A E=\frac{1}{N} * \sum_{i=1}^{N}\left|Y i_{\text {observed }}-Y i_{\text {predict }}\right|$

Where $\mathrm{N}$ shows data numbers and $\mathrm{Yi}$ shows reservoir volume data. The temperature, precipitation, flow and past reservoir volume (lag time, $t-1$ ) of the Stony Brook dam were taken as input data.

In the ANN, GRNN and MLR models, total data has 5326 (from 2012 to 2017) daily records. First of 3726 daily data utilized for training and remaining 1600 daily data for testing. The results obtained with the model were compared with the measured values. 


\subsubsection{Multiple linear regression (MLR) Results}

Multiple linear regression (MLR) analysis is a type of analysis for estimating the dependent variable, depending on 2 or more independent variables associated with the dependent variable. In multiple linear regression, the relationship between multiple independent variables $(\mathrm{X} 1, \mathrm{X} 2, \ldots, \mathrm{Xn})$ and a dependent variable $(\mathrm{y})$ is examined.

In Figure 2 and 3, the daily dam reservoir volume estimates obtained with the MLR model and measurement values given for the test process were compared. The scattering diagram of the measured values and the MLR estimation results for the test data is given in Figure 3.

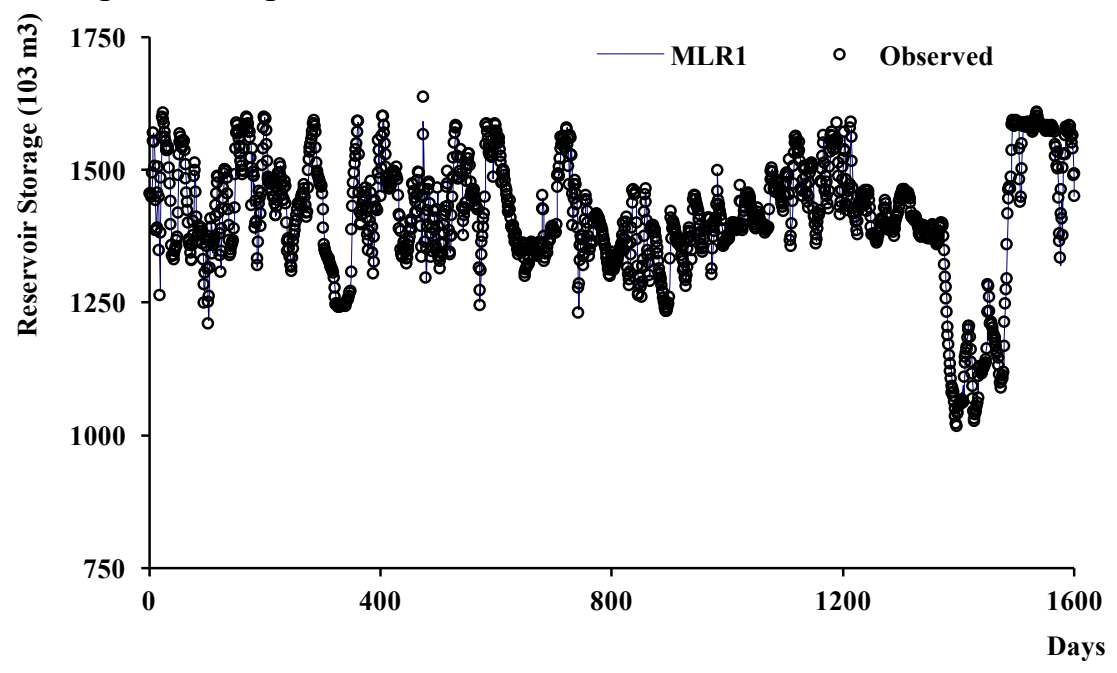

Fig. 2. Measurement and MLR scatter chart for dam reservoir test data

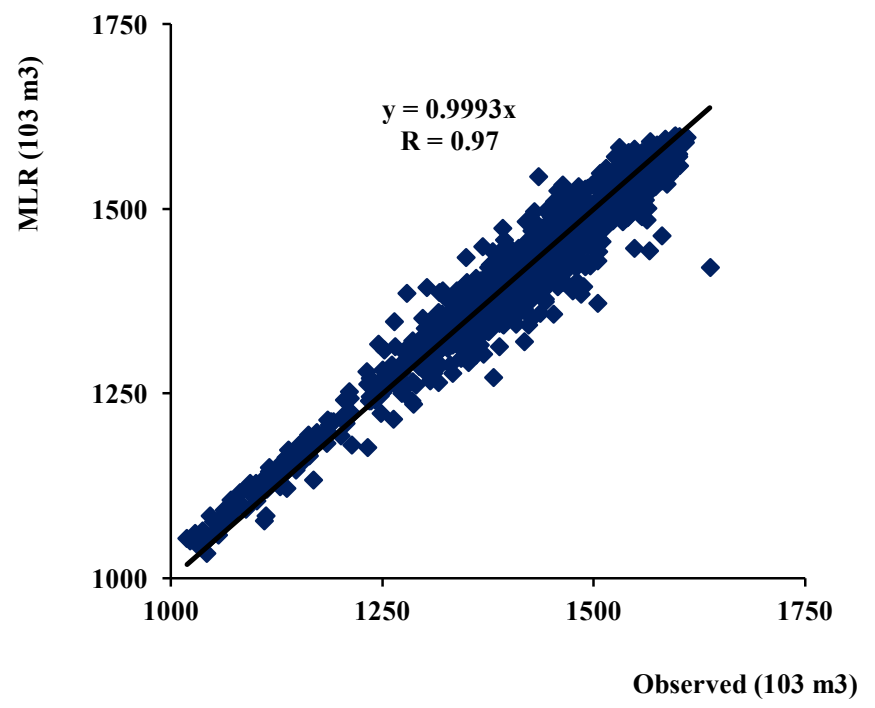

Fig. 3. Measurement and MLR scatter plot for dam reservoir test data 
When we look at the distribution graph in Figure 2, it was observed that there was a very great affinity between the MLR values and the actual measured values. As shown in Figure 3, the correlation coefficient obtained as $\mathrm{R}=0.97$.

\subsubsection{Artificial Neural Networks (ANNs) Results}

In this study, a hidden layer MLP (Multilayer perceptron) was selected while defining the reservoir volume problem in ANN. Backward propagation algorithm (BPA), the most common learning method of MLP, was used for input and output data set.

The forward-fed Bayesian sequentialization propagation algorithm is written with the MATLAB code using the Marquardt Levenberg Method.

In order to develop dam reservoir models, ANN was trained with the use of the first data set, in other words, the training data consisting of 3726 day observations. After the completion of the training phase, the MLPs were applied to the test data consisting of the last 1600-day observations.

In Figure 4, for the test process, ANN reservoir volume estimations and measurement values are compared and in Figure 5 this relationship is given in the scatter diagram format.

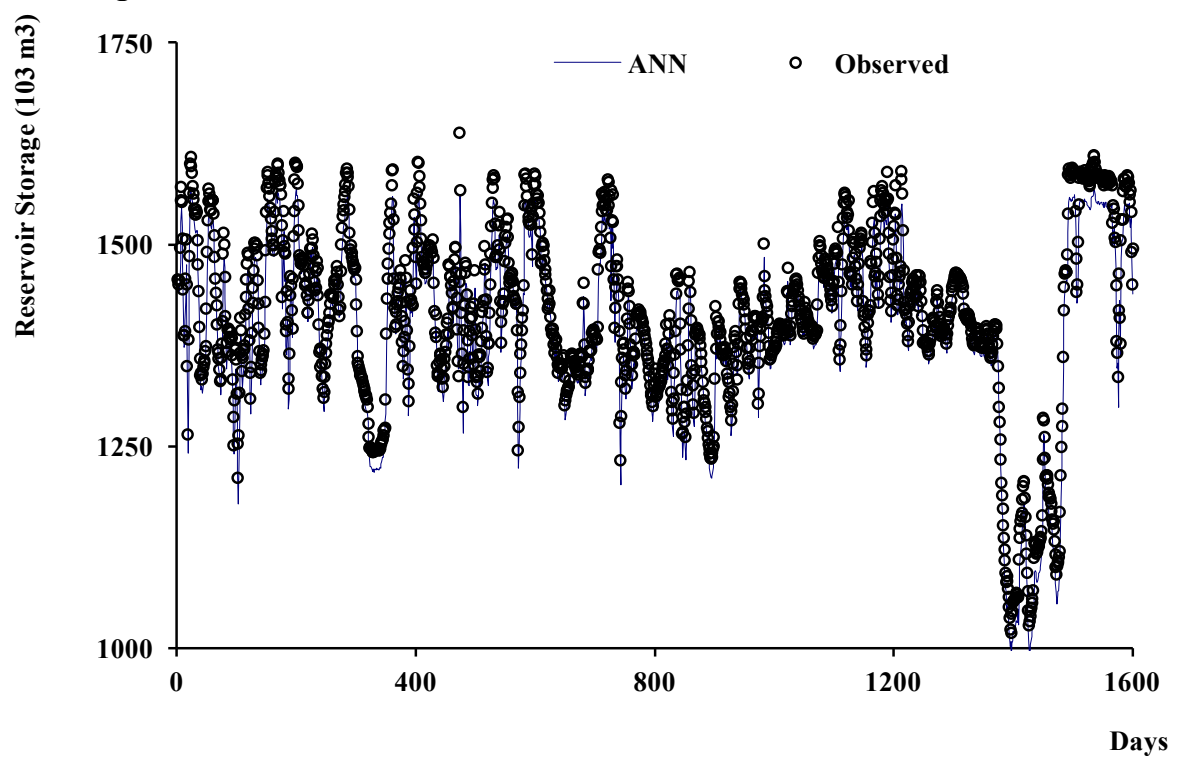

Fig. 4. Measurement and ANN distribution chart for dam reservoir volume test data

As can be seen from Figure 4, the ANN model showed compatibility with the observed reservoir volume. As shown in Figure 5, a very high correlation coefficient $(\mathrm{R}=0.98)$ was obtained. 


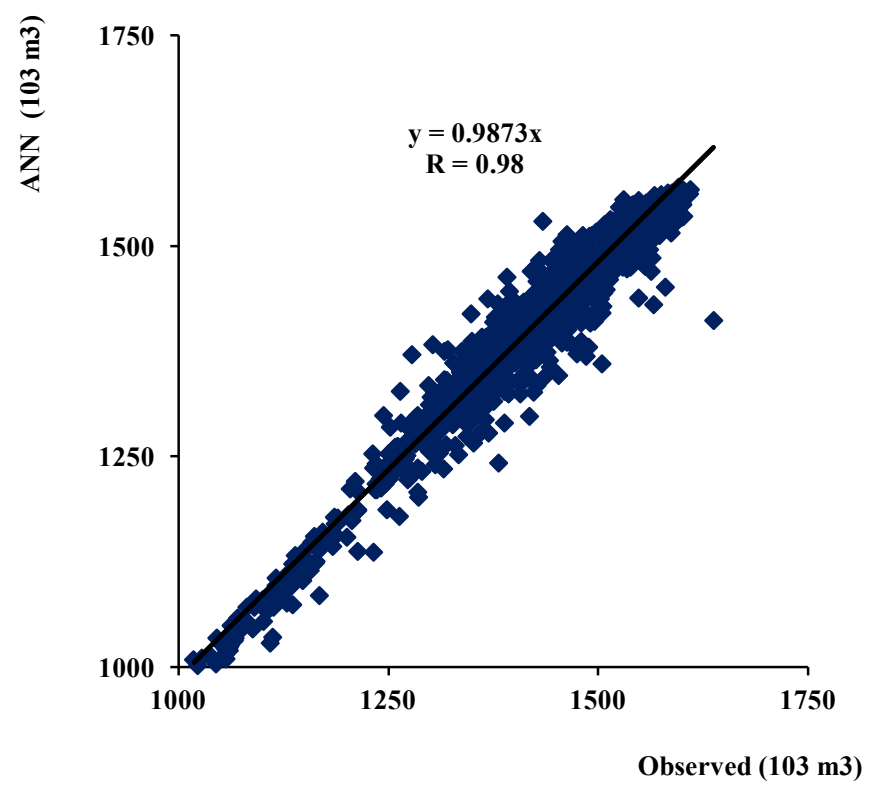

Fig. 5. Measurement and ANN scatter chart for dam reservoir volume test data

\subsubsection{Generalized Regression Neural Networks (GRNN) Results}

The Generalized Regression Neural Networks is another popular ANNs for predicting software reliability more realistically. The GRNN architecture consist of a radial basis layer and special linear layer used for function approximation with sufficient number of hidden neurons.

Any optional function between input and output vectors is derived directly from training data. GRNN is based on nonlinear regression theory for function estimation. The training set consists of $\mathrm{x}$ input values, each of which has a corresponding value of $y$ output. This regression method estimates the y value.

In order to develop dam reservoir volume models, GRNN was trained with the use of the first data set, in other words, the training data consisting of 3726 daily observations.

After the completion of the training phase, the GRNN model were applied to the test data consisting of the last 1600-day observations.

In Figure 6, for the test process, GRNN reservoir volume estimations and measurement values are compared and in Figure 7 this relationship is given in the scatter diagram format.

As it can be seen from Figure 6, the GRNN model showed compatibility with the observed reservoir volume. As shown in Figure 7, a very high correlation coefficient $(\mathrm{R}=0.93)$ was obtained. 


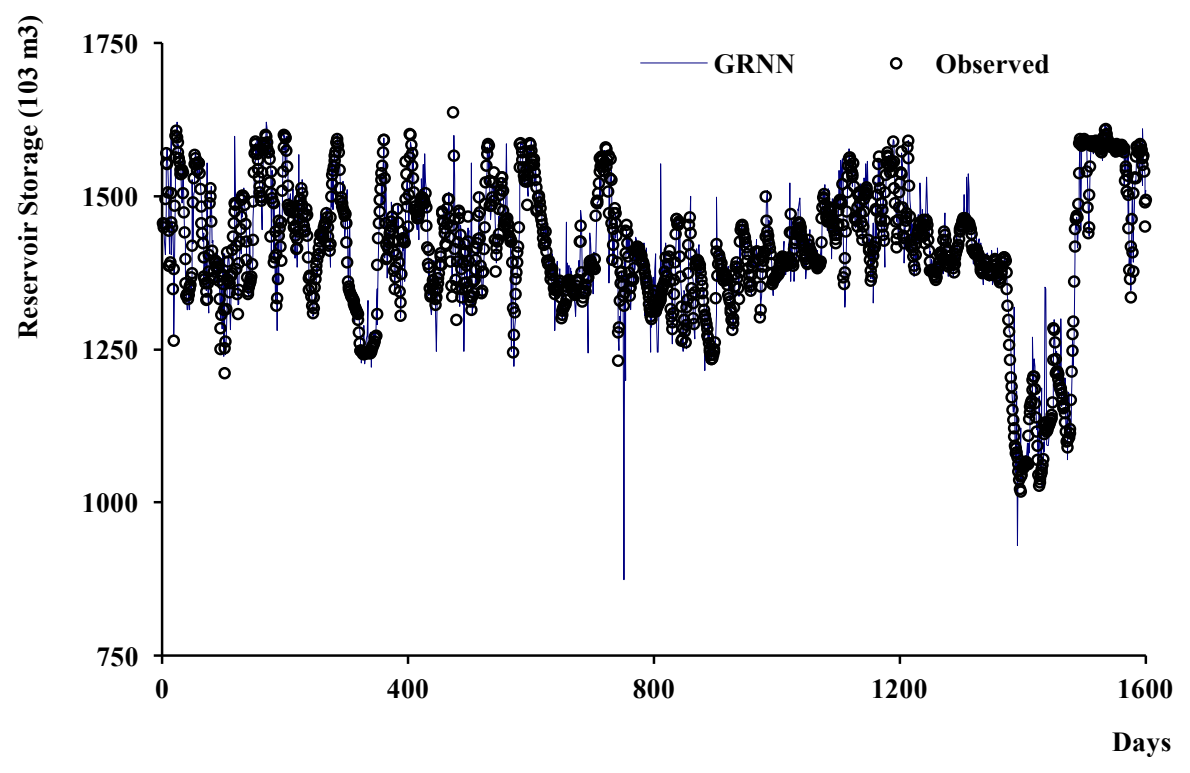

Fig. 6. Measurement and ANN distribution chart for dam reservoir volume test data

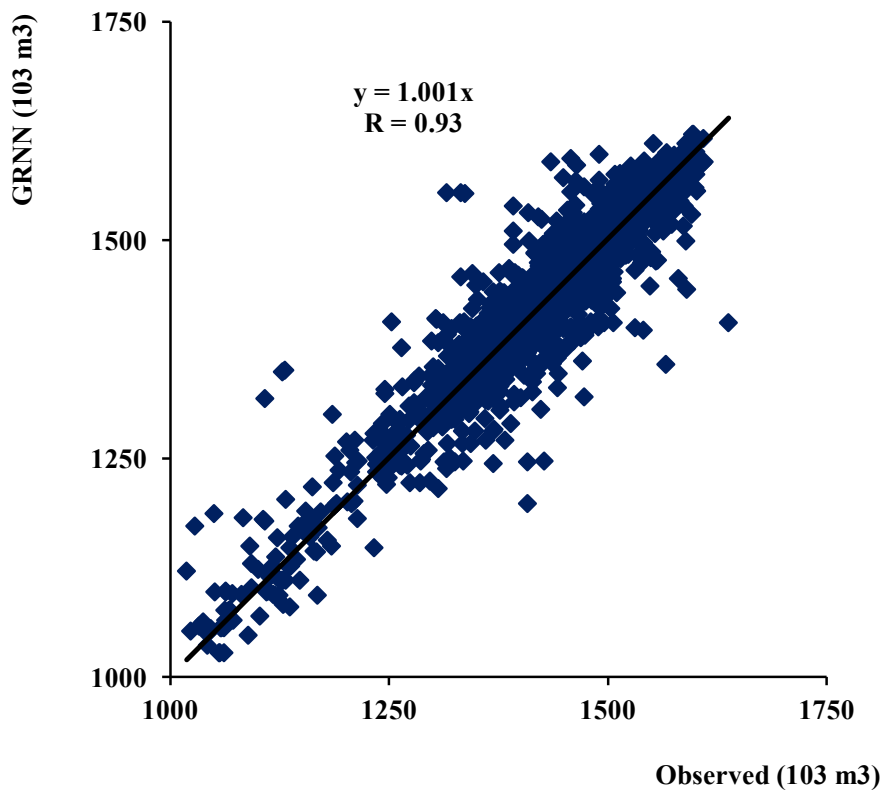

Fig. 7. Measurement and ANN scatter chart for dam reservoir volume test data

\subsubsection{General evaluation}

Correlation coefficient (R), mean square error (MSE) and absolute mean error (MAE) were calculated for the performance evaluation of MLR and ANN models. 
The results were used to compare the performance of the model estimation and the observation data. Comparison of MSE, MAE and R parameters obtained from test data is shown in Table 1 .

Table 1. Performance of MLR and ANN models

\begin{tabular}{|l|l|c|c|c|}
\hline \multicolumn{1}{|c|}{ Methods } & Method Inputs & MSE & MAE & R \\
\hline MLR & $\mathrm{T}_{\mathrm{t}}, \mathrm{Q}_{\mathrm{t}}, \mathrm{P}_{\mathrm{t}}, \mathrm{RV}_{\mathrm{t}-1}$ & 572.3 & 15.78 & 0.97 \\
\hline ANN & $\mathrm{T}_{\mathrm{t}}, \mathrm{Q}_{\mathrm{t}}, \mathrm{P}_{\mathrm{t}}, \mathrm{RV}_{\mathrm{t}-1}$ & 542.9 & 15.67 & 0.98 \\
\hline GRNN & $\mathrm{T}_{\mathrm{t}}, \mathrm{Q}_{\mathrm{t}}, \mathrm{P}_{\mathrm{t}}, \mathrm{RV}_{\mathrm{t}-1}$ & 1722.3 & 27.15 & 0.93 \\
\hline
\end{tabular}

MSE: Mean square error, MAE: Absolute mean error, R: Correlation coefficient

Table 1 shows the test process and each combination of MSE, MAE and Correlation Coefficient (R). When Table 1 is examined, it is seen that the most suitable model for the test data is the ANN model. the highest correlation $(\mathrm{R}=0.981)$ and lowest MSE (15.67) and MAE (524.92) values were computed for mentioned model.

\section{CONCLUSIONS}

In this study, Stony Brook dam reservoir volume, were tried to be estimated with using temperature, precipitation and discharge data. For the estimation of reservoir capacity, ANN and MLR models were used and the models were compared.

The multiple linear regression model (MLR), which is frequently used to describe empirical bonds, yielded very accurate results in solving the problem. Nevertheless, it was observed that the performance of ANN was better than that the MLR model.

ANN is adapted to varying input conditions such as changes in water planning required in the dam reservoir. The reason why ANN is more advantageous than conventional methods in predicting reservoir volume can be explained as the inclusion of the non-linear dynamics and all datasets of the ANN structure. This is quite important, because similar sudden changes in time series can be observed with reservoir operation management studies.

\section{REFERENCES}

1. Chen, D.C., 2012. Daily Reference Evapotranspiration Estimation Based on Least Squares Support Vector Machines. Comput. Comput. Technol. Agric. V, Pt Ii 369, 54-63.

2. Cigizoglu, H.K., 2004. Estimation and forecasting of daily suspended sediment data by multi layer perceptrons. Advances in Water Resources 27, 185-195.

3. Campolo, M., Andreussi, P., Soldati, A., 1999. River flood forecasting wiht a neural network model. Water Resour. Res. 35(4), 1191-1197. 
4. Dawson, C. W., and Wilby, R., 1998. An artificial neural network approach to rainfallrunoff modeling. Hydrological Sci., 43(1), 47-66.

5. Demirci, M., Taşar, B., Kaya, Y.Z., 2018a. Estimation of Groundwater Level Fluctuations Using Neuro-Fuzzy and Support Vector Regression Models. Int. J. Adv. Eng. Res. Sci. 5, 206-211. doi:10.22161/ijaers.5.12.29

6. Demirci, M., Üneş, F., Kaya, Y.Z., Tasar, B., Varçin, H., 2018b. Modeling Of Dam Reservoir Volume Using Adaptive Neuro Fuzzy Method, in: 10th International Water and Air Components Conference. Sovata,ROMANIA, pp. 145-152.

7. Halff, A. H., Halff, H. M., and Azmoodeh, M., 1993. Predicting runoff from rainfall using neural networks. Proc., Engrg. Hydrol., ASCE, New York, 760-765.

8. Hsu, K., Gupta, H. V., and Sorooshian, S., 1995. Artificial neural network modeling of the rainfall-runoff process. Water Resour. Res., 31(10), 2517-2530.

9. Imrie, C.E., Durucan, S., Kore, A., 2000. River flow prediction using artificial neural networks: generalization beyond the calibration range. J. Hydrol. 233, 138-153

10. Jain A., Sudheer K.P., and Srinivasulu S., 2004. Identification of physical processes inherent in artificial neural network rainfall runoff models. Hydrological Processes 18 (3): 571-581.

11. Kaya, Y.Z., Üneş, F., Demirci, M., Tasar, B., Varçin, H., 2018. Groundwater Level Prediction Using Artificial Neural Network And M5 Tree Models, in: 10th International Water and Air Components Conference. Sovata, ROMANIA, pp. 195-201.

12. Kaya, Y.Z., Taşar, B. (2019) Evapotranspiration Calculation for South Carolina, USA and Creation Different ANFIS Models for ET Estimation. 2019 "Air and Water Components of the Environment" Conference Proceedings, Cluj-Napoca, Romania, p. 217-224, DOI: 10.24193/AWC2019_22.

13. Karunanithi, N., Grenney, W. J., Whitley, D., and Bovee, K., 1994. Neural networks for river flow prediction. J. Comp. in Civ. Engrg., ASCE, 8(2), 201-220.

14. Kisi, O., 2004, Multi-layer perceptrons with Levenberg-Marquardt training algorithm for suspended sediment concentration prediction and estimation. Hydrological Sciences-Journal-des Sciences Hydrologiques, 49(6).

15. Kumar, M., Raghuwanshi, N. S., Singh, R., Wallender, W. W., Pruitt W. O., 2002, Estimating Evapotranspiration using Artificial Neural Network. Journal of Irrigation and Drainage Engineering, 224.

16. Nivesh S., Kumar P., Sawant P., Verma R. (2018), Application of Fuzzy Logic and Statistical Approaches for Estimation of Suspended Sediment Concentration. Int. J. Curr. Microbiol. App. Sci, 7(2), 3716-3733.

17. Rajurkar, M.P., Kothyari, U.C, and Chaube, U.J., 2004, Modeling Daily Rainfall- Runoff Relationship with Artificial Neural Network, Journal Of Hydrology, 285, 96-113.

18. Smith, J., and Eli, R. N., 1995. Neural-network models of rainfall-runoff process. J. Water Resour. Plng. and Mgmt., ASCE, 121(6), 499-508.

19. Solomatine, D. P., and Dulal, K. N., 2003. Model trees as an alternative to neural networks in rainfall-runoff modeling, Hydrol. Sci. J. 48(3), 399-411.

20. Sudheer, K.P., and Jain A., 2004. Explaining the internal behaviour of artificial neural network river flow models. Hydrological Processes 18 (4): 833-844.

21. Sudheer K.P., 2005. Knowledge extraction from trained neural network river flow models, Journal of Hydrologic Engineering 10 (4): 264-269.

22. Talei, A., Hock, L., Chua, C., Quek, C., Jansson, P., 2013. Runoff forecasting using a Takagi - Sugeno neuro-fuzzy model with online learning. J. Hydrol. 488, 17-32. doi:10.1016/j.jhydrol.2013.02.022 
23. Taşar, B., Kaya, Y.Z., Varçin, H., Üneş, F., Demirci, M., 2017. Forecasting of Suspended Sediment in Rivers Using Artificial Neural Networks Approach. Int. J. Adv. Eng. Res. Sci. 4, 79-84. doi:10.22161/ijaers.4.12.14

24. Tasar B., Unes F., Demirci M., Kaya Y.Z. (2018), Yapay sinir ağları yöntemi kullanılarak buharlaşma miktarı tahmini. DÜMF Mühendislik Dergisi, 9(1), 543-551.

25. Üneş, F., Yıldırım, S., Cigizoğlu, H.K., Coşkun H. (2013). Estimation of Dam Reservoir Volume Fluctuations Using Neural Network and Support Vector Regression. Journal of Engg. Research, 1(3), 53-74.

26. Üneş, F., Joksimovic, D., Kisi, O., 2015b. Plunging Flow Depth Estimation in a Stratified Dam Reservoir Using Neuro-Fuzzy Technique. Water Resour. Manag. doi:10.1007/s11269-015-0978-y

27. Üneş, F., Bölük, O., Kaya, Y.Z., Taşar, B., Varçin, H., (2018a). Estimation of RainfallRunoff Relationship Using Artificial Neural Network Models for Muskegon Basin. Int. J. Adv. Eng. Res. Sci. 6, 198-205. doi:10.22161/ijaers.5.12.28

28. Üneş F., Doğan S., Taşar B., Kaya Y., Demirci M. (2018b), The Evaluation and Comparison of Daily Reference Evapotranspiration with ANN and Empirical Methods. Natural and Engineering Sciences, 3(3), Supplement, 54-64.

29. Üneş, F., Demirci, M., Taşar, B., Kaya, Y. Z., \& Varçin, H. (2019a). Estimating Dam Reservoir Level Fluctuations Using Data-Driven Techniques. Polish Journal of Environmental Studies, 28(5).

30. Unes, F., Demirci, M., Tasar, B., Kaya, Y. Z., \& Varçin, H. (2019b). Modeling of dam reservoir volume using generalized regression neural network, support vector machines and M5 decision tree models. Applied Ecology And Environmental Research, 17(3): 7043-7055. DOI: http://dx.doi.org/10.15666/aeer/1703_70437055

31. Wilby, R. L., Abrahart, R. J., and Dawson, C. W., 2003. Detection of conceptual model rainfall-runoff processes inside an artificial neural network. Hydrol. Sci. J. 48(2), 163181.

32. *** (2020), Google Maps, accessed February 15, 2020. 